\title{
WACANA KESENIAN GENJEK
}

Oleh : I Wayan Sugita

\begin{abstract}
Abstrak
Kesenian genjek ini tergolong jenis kesenian tradisional Bali yang memadukan antara seni suara dengan seni musik tradisional Bali yang dapat digolongkan sebagai etnomusikologi. Genjek sebagai salah satu kesenian tradisional yang memadukan antara kesenian musik tradisional dengan seni suara ini juga mempunyai ekspresi, nilai, dan pesan yang ingin disampaikan lewat syairsyair lagu yang dinyanyikan itu. Nilai dan pesan itu dapat berupa kritik sosial, percintaan, nasihat, dan bahkan mungkin ada yang bersifat religius. Dalam tulisan ini dicoba untuk mengkaji bentuk, fungsi, dan makna pada wacana kesenian genjek dengan menggunakan teori ethnography speaking oleh Dell Hymes (1972). Adapun sumber data tulisan ini adalah data lisan yang telah direkam dalam bentuk kaset rekaman dan telah banyak diperjualbelikan di toko-toko kaset. Berdasarkan kajian yang telah dilakukan dapat dikatakan bahwa bentuk wacana kesenian genjek di Bali ini berupa syair lagu yang dikemas dengan menggunakan bahasa Bali. Pemilihan bentuk bahasanya disesuikan dengan pesan nilai yang ingin disampaikan. Fungsi wacana kesenian genjek ini selain sebagai hiburan, juga sebagai sarana untuk menyampaikan pesan terhadap gejala kemasyarakatan yang sedang berkembang.

Makna wacana kesenian genjek ini adalah untuk memperoleh kesadaran warga masyarakat dan dapat melakukan introspeksi diri dalam berperilaku sosial.
\end{abstract}

Kata kunci: wacana, kesenian genjek

\section{Pendahuluan}

Keberadaan kesenian daerah Bali sampai saat ini telah mengalami peningkatan, tidak hanya secara kualitas tetapi juga kuantitasnya. Hal itu dapat dilihat dengan banyaknya muncul kesenian baru yang dapat memberikan suatu corak pembaruan di dalam proses berkesenian. Salah satunya adalah kesenian genjek.

Kesenian genjek ini tergolong jenis kesenian tradisional Bali yang memadukan antara seni suara dengan seni musik tradisional Bali. Selain memadukan kedua jenis kesenian tersebut, kesenian genjek ini dalam proses kreatifnya ada pula yang diiringi dengan gerak tari. Namun, gerak tarinya sangat sederhana dan hanya menyerupai sebuah tarian kecak. Dengan demikian, dapatlah dikatakan bahwa kesenian genjek ini adalah suatu bagian dari etnomusikologi

Menurut Alan Marriam dalam Beresford (1983:5), etnomusikologi adalah studi tentang musik dan kebudayaan. Berdasarkan definisi di atas secara implisit dapat diasumsikan bahwa mengingat suara musik adalah hasil dari proses tindakan manusia, maka kedua hal itu tidak dapat dipisahkan karena saling berhubungan. Dengan demikian, sumbangan etnomusikologi terhadap pengetahuan manusia ialah bahwa ia mempersatukan studi tentang manusia dengan musik sehingga dapat dirasakan fungsi musik

${ }^{1}$ Dr. Drs. I Wayan Sugita,M.Si Dosen Pendidikan Bahasa dan Sastra Agama IHDN Denpasar. 
itu sendiri sebagai alat untuk memahami segisegi lain.dari kebudayaan. Dengan kata lain, musik adalah alat komunikasi yang kompleks untuk menyampaikan sebuah ekspresi jiwa.

Dikaitkan definisi di atas, genjek sebagai salah satu kesenian tradisional yang memadukan antara kesenian musik tradisional dengan seni suara ini juga mempunyai ekspresi, nilai, dan pesan yang ingin disampaikan lewat syairsyair lagu yang dinyanyikan itu. Nilai dan pesan itu dapat berupa kritik sosial, percintaan, nasihat, dan bahkan mungkin ada yang bersifat religius. Dengan demikian, dewasa ini kesenian genjek itu sudah mengalami suatu transformasi.

Kalau dulu kesenian genjek ini identik dengan minuman keras seperti nira (tuak) karena kesenian ini pada mulanya dilakukan pada saat minum tuak, kini telah berubah sebagai wahana untuk menyampaikan pesan lewat nyanyian.

Berdasarkan latar belakang di atas, wacana genjek ini sangat menarik untuk dikaji lebih mendalam agar kesenian genjek ini tidak dilihat hanya dengan sebelah mata. Adapun masalah yang dikaji pada kajian ini diformulasaikan dalam bentuk pertanyaan sebagai berikut. (1) Bagaimana bentuk wacana genjek itu? (2) Bagaimana fungsi wacana genjek itu? (3) Bagaimana makna wacana genjekitu?

Sesuai dengan judul tulisan ini yang mengambil topik wacana genjek, maka teori yang digunakan adalah teori etnografi komunikasi. Etnografi itu sendiri diartikan sebagai kajian tentang kehidupan dan kebudayaan suatu masyarakat atau kelompok etnis, misalnya tentang adat istiadat, kebiasaan, hukum, seni, religi, dan bahasa. Apabila dikaitkan dengan pengertian di atas, etnografi komukasi merupakan kajian yang memerikan suatu masyarakat atau kelompok etnis dalam berkomunikasi. Atau dengan kata lain, pemerian etnografi itu bisa diterapkan dan difokuskan kepada bahasa masyarakat atau kelompok tersebut.

Pada awalnya, istilah etnografi komunikasi dimunculkan dengan istilah ethnography speaking oleh Dell Hymes (1972). Beliau menggambakan etnografi berbahasa itu dalam bentuk akronim bahasa Inggris, yaitu SPEAKING.

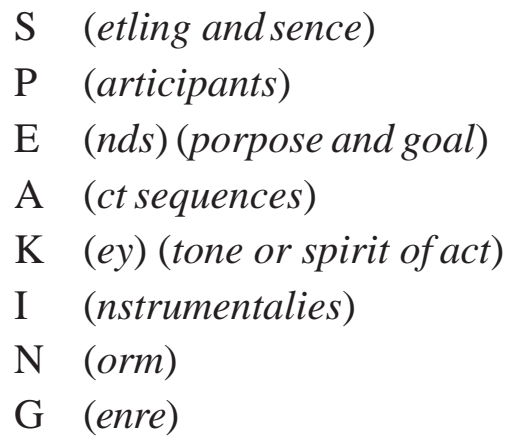

Di antara komponen yang disebutkan di atas. yang paling doininan dan menonjol berperan adalah seting, topik, dan partisipan. Konstalasi ketiganya melahirkan ranah. Ketiga unsur di atas itulah nantinya yang digunakan sebagai untuk menganalisis wacana kesenian genjek di Bali. Selanjutnya, untuk mengungkapkan makna yang tersirat pada wacana genjek itu diterapkan teori semiotik sosial oleh Hodge dan Kress (1988), dalam bukunya yang berjudul Social Semiotics. Hodge dan Kress menyebutkan bahwa semantik sosial merupakan kajian umum tentang semiotic, yaitu proses, efek, produksi, penerimaan, dan sirkulasi makna dalam semua bentuk yang digunakan oleh semua manusia dalam berkomunikasi.

Sumber data tulisan ini adalah lisan yang telah direkam dalam bentuk kaset rekaman dan telah banyak diperjualbelikan di toko-toko 
kaset. Dari sejumlah kaset rekaman tentang genjek itu dipilih beberapa kaset yang diambil dari kelompok atau sekaa genjek yang telah memiliki nama dan sudah banyak dikenal masyarakat Bali.

Metode yang diterapkan dalam tulisan ini dibedakan menjadi tiga tahapan, yaitu (1) metode pengumpulan data, (2) metode pengolahan data dan (3) metode penyajian hasil analisis. Metode pengumpulan data dilakukan dengan mentranskripsi rekaman kesenian genjek dari bentuk rekaman ke dalam tulisan. Setelah semua tertranskripsikan, data diolah dan diklasifikasi. Adapun metode yang digunakan di dalam pengklasifikasian data adalah dengan jalan mengelompokkan syairsyair yang terdapat dalam wacana genjek itu sesuai dengan tema dan pesan yang disampaikan. Terakhir, penyajian hasil analisis dilakukan dengan menggunakan metode informal, yaitu penyajian dengan hasil analisis dengan menggunakan kata-kata biasa.

\section{Wacana Kesenian Genjek}

Pada bagian pendahuluan telah disinggung sekilas bahwa kesenian genjek ini merupakan salah satu jenis kesenian Bali yang memadukan unsur seni suara seperti (nyanyian), musik tradisional (gamelan), dan selingan tarian. Melalui syair lagu yang dinyanyikan itu ada beberapa pesan dan nilai yang ingin disampaikan kepada para penikmatnya. Dengan katalain, penikmat di sini, selain terhibur oleh pertunjukan kesenian genjek itu sendiri, dapat pula memetik nilai-nilai yang tersirat pada syair lagu yang dinyanyikan tersebut. Berdasarkan data sementara yang terkumpul, pesan kesenian genjek itu dapat dikelompokkan atas beberapa kelompok, yaitu (1) syair yang mengandung nilai percintaan, (2) kritik sosial, (3) politik, dan (4) nasihat. Masing-masing wacana genjek yang dimaksud diuraikan sebagai berikut.

\subsection{Nilai Percintaan}

Wacana kesenian genjek yang mengandung nilai percintaan ini paling banyak ditemukan. Hal itu berarti bahwa para pemain kesenian genjek ini didominasi oleh generasi muda sehingga syair-syaimya ada kecenderungan melukiskan kegiatan sepasang muda-mudi yang sedang memadu kasih. Dengan kata lain, syair lagunya cenderung romantis seperti terlihat pada kutipan syair berikutini.

Ni Luh Ani dong pirengang omong beliné

Bes keliwat tresnan beli kapining adi Tuara sida Beli pacang mangengsapin Dong tulusang tulungin déwék beliné Apang nu beli idup di guminé Beli Putu sampunang sumanangsaya Titiang nyadia pacang ngenyakin beli

Nanging adi da nyelselang déwék beliné Beli tiwas tuara ngelah arta brana Cucud asih anggo beli manyayangang Jelé melah apang sida bareng-bareng

Teriemahan:

'Ni Luh Ani dengarlah perkataan kanda' Terlalu besar cinta kanda kepadamu

Tidak dapat kanda melupakanmu

Tolonglah kanda ini

Agar kanda dapat menyambung hidup

Kanda Putu janganlah ragu

Dinda bersedia menuruti kanda

Tetapi dinda jangan menyalahkan kanda

Kanda tidak punya harta benda 
Hanya cinta kasih yang kanda miliki

Suka dan duka hidup bersama-sama'

\subsubsection{Bentuk}

Bentuk wacana kesenian genjek yang mengandung miai pesan percintaan ini menggunakan bahasa Bali biasa atau lumrah. Pemilihan bentuk bahasa seperti itu didasarkan atas partisipan yang terlibat pada dialog syair itu vaiiu sepasang muda-mudi yang bersifat horizontal. Maksudnya hubungan antara pembicara satu dengan pembicara yang lainnya memperlihatkan hubungan yang sangat akrab.Hal itu terlihat dan pemilihan bentuk pemilihan katanya, seperti penggunaan bentuk sapaan adi dinda dan belt kanda yang terlihat pada kutipan di atas.

\subsubsection{Fungsi}

Fungsi wacana kesenian genjek ini terkait dengan siapa pelaku dan kapan muncul wacana scperil itu. Berdasarkan kedua hal itu, lungsi wacana kesenian genjek yang melukiskan pesan percintaan ini diucapkan muda-mudi yang sedang kasmaran. Dengan kata lain, fungsi wacana kesenian genjek yang mengandung pesan percintaan ini adalah sebagai sarana untuk mengungkapkan isi seorang pemuda kepada pemudi.

\subsubsection{Makna}

Berdasarkan kutipan di atas, secara eksplisit wacana kesenian genjek yang melukiskan nilai pesan percintaan ini adalah bermakna untuk mernohon kesediaan dari seorang pemudi untuk menerima cinta kasih seorang pemuda. Meskipun pemuda tersebut tidak kaya dan hanya bermodalkan cinta kasih. Hal itu terlihat dan ungkapan bes kaliwat tresnan beli kapining adi 'teramat besar cinta kanda kepada dinda', beli tiwas tuara ngelah arta berana 'kanda miskin tidak punya harta benda' dan cucud asih anggo beli menyayangang 'cintakasihyang kanda miliki'.

\subsection{Nilai KritikSosial}

Seperti telah diuraikan di atas, salah satu pesan yang disampaikan pada wacana kesenian genjek adalah nilai pesan kritik sosial. Nilai kritik sosial ini terkait erat dengan perilaku sosial yang sedang menggejala pada masyarakat Bali khususnya. Menyimpang dari norma-norma yang ada pada masyarakat Bali. Untuk lebih jelasnya, hal itu dapat disimak pada contoh wacana berikut.

De ja bes sanget sombong

Ngandel kén déwék jegeg

Peteng lemah pragat mapayas

Nanging tuara nganutin sasana dadi

anak luh bajang

\section{Mara tatas ba nawang \\ Tekén tingkah lakuné \\ Disubané ada anak ngorder \\ Menék sédan lantas tuun hartop \\ Dadi gadis jemputan}

Terjemahan:

Janganlah terlalu sombong Merasa dengan diri cantik Siang malam hanya bersolek Tetapi tidak mencerminkan perilaku seorang gadis

Baru dapat diketahui dengan jelas

Dengan tingkah lakunya

Setelah ada orang yang memesan

Naik kendaraan sedan kemudian turun

Hardtop

Menjadi gadis panggilan 


\subsubsection{Bentuk}

Berdasarkan data di atas, dapat diketahui bahwa bentuk wacana kesenian genjek yang melukiskan nilai kritik sosial ini dikemas dengan menggunakan bahasa Bali biasa atau bahasa Bali lumrah. Penggunaan bentuk bahasa semacam itu mempunyai maksud agar pesan yang disampaikan itu dapat diterima secara mudah. Di samping itu, pemilihan bentuk bahasa seperti itu memiliki nilai rasa yang sesuai dengan luapan emosi yang disampaikan. Secara psikologis orang yang sedang melakukan kritik itu umumnya dalam suasana emosi marah. Dengan demikian, penggunaan bentuk bahasa seperti itu sejalan dengan nilai pesan yang disampaikanitu.

\subsubsection{Fungsi}

Seperti halnya fungsi percintaan, fungsi ini juga berkaitan dengan kepada siapa dan kapan wacana itu ditujukan. Berdasarkan pemahaman fungsi dan kutipan wacana di atas dapat dikatakan bahwa fungsi wacana kesenian genjek yang mengandung nilai pesan kritik sosial ini ditujukan kepada masyarakat Bali, khususnya kalangan wanita yang sudah tidak lagi mengindahkan norma kesusilaan. Maksudnya, ada gejala perilaku wanita Bali yang sudah kehilangan jati dirinya dan tidak lagi mencerminkan budaya Bali, seperti tampak pada kutipan berikut: lemah pragat peteng mapayas 'siang malam hanya bersolek', nanging tuara nganutin sasana dadi anak luh bajang 'tetapi tidak sesuai dengan perilaku seorang gadis'; dan dadi gadis jemputan 'menjadi gadis gadis panggilan'.

\subsubsection{Makna}

Berdasarkan kutipan bentuk wacana di atas, dapat dikatakan bahwa wacana kesenian genjek yang mengandung nilai pesan kritik sosial ini mengandung makna agar penikmat dapat melakukan introspeksi diri. Maksudnya, adalah sebagai sebuah imbauan bahwa berperilaku sebagai gadis panggilan itu tidak sesuai dengan norma sebagai seorang wanita yang mulia.

\subsection{Nilai Politik}

Bergulimya reformasi di TanahAir, ternyata mengilhami syair-syair yang terdapat pada wacana kesenian genjek ini. Hal itu berarti bahwa pesan nilai politik juga mewamai wacana kesenian genjek ini. Sebagai gambaran tentang hal itu dapat disimak pada kutipan syair berikut ini.

gradag-grudug munyin kerugé di langit panjaké makejang pada tusing peduli pacang ngetaohin jagaté né sangsara yadiastun belus lucut ngamélanin wiréh guminé makelo krisis ajin barang makejang pada menék ngawé rakyaté kéweh matingkah ané ngranayang wantah KKN mula musuh di guminé buka jani jalan jani bareng-bareng mabéla pati apa saja misi buka janjin beliné da takut yan madasar ban patut

Terjemahan:

bergemuruh suara petir di angkasa rakyat semua tidak peduli akan menyelamatkan negara dari kesengsaraan walau basah kuyup dalam membelanya bersorak riang menuntut reformasi karena negara mengalami krisis berkepanjangan harga barang semua naik membuat rakyat sulit bertindak 
penyebabnya adalah KKN

sebagai musuh negara saat ini

marilah bersama-sama membela

kebenaran

apa betul sesuai dengan janji kakak

janganlah takut kalau di jalan yang benar

\subsubsection{Bentuk}

Berdasarkan kutipan wacana di atas, dapat diketahui bahwa bentuk wacana kesenian genjek yang melukiskan nilai pesan politik ini dikemas dengan menggunakan bahasa Bali biasa atau lumrah yang dicampur dengan kosakata bahasa bahasa Indonesia. Peminjaman kosakata bahasa Indonesia itu dilakukan karena di dalam kosakata bahasa Bali belum ditemukan padanannya. Dengan kata lain, bentuk bahasa seperti itu dilakukan dengan penuh kesadaran. Jadi, hal itu dilakukan secara integratif. Adapun bentuk-bentuk yang dimaksud adalah peminjaman istilah KKN (korupsi, kolusi, nepotisme) dan reformasi, seperti yang terlihat pada kutipan wacana di atas.

\subsubsection{Fungsi}

Seperti juga halnya fungsi lainnya, fungsi di sini juga berkaitan dengan siapa dan kapan wacana itu diucapkan. Berdasarkan pemahaman fungsi, kutipan wacana kesenian genjek yang mengandung nilai pesan politik itu ditujukan kepada penguasa yang telah melakukan tindakan KKN secara sistematis sehingga tatanan kenegaraan dan kehidupan rakyat menjadi terpuruk. Selain itu, terjadi krisis kepercayaan dari rakyat terhadap penguasa. Hal itu dapat dilihat dan kutipan berikut: panjake pada sing peduli 'rakyat menjadi tidak peduli, ngawé rakyaté kéweh matingkah 'membuat rakyat sulit bertindak', ané ngranayang wantah $K K N$ 'sebagai penyebabnya adalah KKN'.

\subsubsection{Makna}

Berdasarkan bentuk dan fungsi di atas, dapat diketahaui bahwa makna wacana genjek yang mengandung pesan nilai politik itu merupakan sebuah imbauan dari rakyat kecil kepada penguasa agar menghentikan segala macam bentuk KKN dan penyimpangan lainnya. Di samping itu, nilai pesan politik ini juga mempunyai makna bahwa rakyat telah menghendaki adanya sebuah perubahan dengan cara reformasi. Makna itu secara jelas tersirat dalam kutipan berikut: girang mesuryak menuntut reformasi 'bersorak riang menuntut reformasi' dan da ja takut yan madasar ban patut 'janganlah takut kalau di jalan yang benar'.

\subsection{Nilai Nasihat}

Nilai pesan lainnya yang mewamai syair kesenian genjek adalah nilai nasihat. Tema nilai seperti ini banyak sekali ditemukan dalam kesenian genjek. Hal itu membuktikan bahwa kesenian genjek itu di samping menghibur ternyata memiliki nilai-nilai yang luhur berupa petuah orang tua terhadap anak-anaknya. Untuk lebih jelasnya mengenai hal itu dapat dilihat pada kutipan wacana berikutini.

cening ayu selegang cening malajah disubané cening tamat di SMP bapa buin lakar nyekolahang cening ditu di SMAP lan kursus bahasa lnggris disubané cening maan tanda tamat lulus bahasa lautang ja cening majalan di Hotel Indra Udayana cening mengabdi

bapa kangen cening dadi jadma lacur 
to kanggoang patilesang ragan ceningé yan mamunyi patuté palapanin

eda lengit eda sombong

Terjemahann

anakku rajin-rajinlah belajar

setelah lulus di SMP

ayah akan menyekolahkanmu

di SMAP dan kursus bahasa lnggris

setelah selesai kursus bahasa lnggris

silahkanlah kamu mencari pekeijaan

di Hotel Indra Udayana kamu

mengabdikan diri

Bapak merasa sedih kamu jadi orang

miskin

terimalah dan beriskaplah rendah hati

hati-hatilah dalam ucapan

jangan malas dan jangan sombong

\subsubsection{Bentuk}

Berdasarkan kutipan wacana di atas, dapat diketahui bahwa bentuk wacana kesenian genjek yang mengandung pesan nilai nasihat ini dikemas dengan menggunakan bahasa Bali biasa atau bahasa lumrah. Pemilihan bentuk bahasa seperti itu sesuai dengan pelibatnya, yaitu antara orang tua kepada anaknya. Dengan kata lain hubungan komunikasi yang terjadi bersiafat vertikal. Dalam hal ini komunikasi teijadi dari atas ke bawah. Hubungan seperti itu menuntut adanya pemakaian bentuk bahasa ragam biasa atau. Akan berbeda halnya jika komunikasi terjadi sebaliknya dari bawah ke atas, pemakaian bentuk bahasa Bali lumrah tidaklah tepat.

\subsubsection{Fungsi}

Berdasarkan bentuk dan kutipan wacana di atas, dapat diketahui wacana kesenian genjek yang mengandung pesan nilai nasihat ini adalah sehingga upaya orang tua memberikan petuah-petuah kepada anak-anaknya. Adapun petuah yang dimaksud dapat disimak pada kutipan berikut: yén mamunyi patuté palapanin 'hati-hatilah dalam ucapan'; eda lengit eda sombong 'jangan malas dan jangan sombong'

\subsubsection{Makna}

Berdasarkan bentuk dan fungsi di atas, dapat dikatakan bahwa makna wacana kesenian genjek yang mengandung nilai nasihat secara tersirat adalah agar penikmat, khususnya anak-anak dapat melakukan instropeksi diri untuk berperilaku yang baik. Dengan kata lain mereka dapat mengetahui tugas dan kewajibannya sebagai anak yang mencerminkan anak yang suputra. Makna itu dapat dilihat pada kutipan berikut: cening ayu selegang cening malajah 'anakku rajin-rajiniah belajar'; to kanggoang petilesang ragan ceningé 'terimalah dan bersikaplah rendah hati'; yén memunyi patuté palapanin 'berhatihatilah dalam ucapan'; da lengit da sombong 'jangan malas dan jangan sombong'.

\section{Simpulan}

Berdasarkan uraian di atas, dapat disimpulkan hal-hal sebagai berikut

(1) Bentuk wacana kesenian genjek di Bali ini berupa syair lagu yang dikemas dengan menggunakan bahasa Bali. Pemilihan bentuk bahasanya disesuikan dengan pesan nilai yang ingin disampaikan.

(2) Fungsi wacana kesenian genjek ini selain sebagai hiburan, juga sebagai sarana untuk menyampaikan pesan terhadap gejala kemasyarakatan yang sedang berkembang. 
(3) Makna wacana kesenian genjek ini adalah untuk memperoleh kesadaran warga masyarakat dan dapat melakukan introspeksi diri dalam berperilaku sosial.

\section{Daftar Pustaka}

Beresford Annete Edith. 1983. Perihal Transmisi Budaya Musik dan Tan di Pedesaan Bali. Denpasar: Jurusan Antropologi Fakultas Sastra Universitas Udayana.

Hodge, Robert dan Kress Gather. 1988. Social Semiotics. Oxford: Polity Press 
Kaplan, David dan Albert A. Menners. 1988. Teori Budaya. Yogyakarta: Pustaka Pelajar.

Nababan, P W.J 1991. Sosiolinguistik: Suatu Pengantar. Jakarta: PT Gramedia.

Piaget, Jean.1995. Strukturalisme. Jakarta: Yayasan Obor.

Saussure, Ferdinand de 1993. Pengantar Lingusitik Umum. Yogyakarta: Gadjah Mada University Press.

Van Peursen, C.A 1988. Strategi Kebudayaan. Yogyakarta 